\title{
A Review on Parameters of Internet Gateway Discovery in MANETS
}

https://doi.org/10.3991/ijoe.v17i08.24597

\author{
Husna Osman( $\left.{ }^{\bowtie}\right)$, Mufind Mukaz Ebedon, Amna Saad \\ Universiti Kuala Lumpur, Kuala Lumpur, Malaysia \\ husna@unikl.edu.my
}

\begin{abstract}
Mobile ad hoc Networks researchers need to apply specific parameters in the simulation tools chosen to analyze and discuss their results. The challenge faced by multiple authors is on how to decide on the choice of particular parameters. A wrong choice could lead to a no credible result and a doubtful result by other researchers. A best practice is to follow what other authors are using as input parameters in their paper. This review analyses 72 proceeding papers and articles in different digital libraries: google scholar, IEEE Xplore, Elsevier, Springer, and snowball from 2010-2020. We present the result of our survey in this paper. We recommend the input parameters research should use base on the high utilization. Our review will also help the community in MANET and Internet gateway to improve the credibility of the input parameters.
\end{abstract}

Keywords-MANET, routing protocols, mobility model, metric, simulation tool, performance

\section{Introduction}

Mobile ad hoc networks (MANET) is a self-construction network that depends only on the node to form a network on the go. The MANET node has a double function; they can be routers and sender at the same time. MANET communication has many challenges based on the network's formation, which involves a rapid change of the topology, battery drainage, and link breakdown. Base on all the challenges mentioned above, scholars have created different protocols to improve communication in MANE. They developed proactive protocol [1], reactive protocol [2], and hybrid protocol [3].

The mobile ad hoc network cannot only rely on internal communication within the MANET. Sometimes node needs to communicate with other nodes outside the MANET, which is on the Internet (infrastructure network), to extend the communication. A mobile node in MANET needs to discover and communicate with the Internet gateway (IGW), which acts as hybrid equipment that understands both Infrastructure network and no infrastructure network (MANET). The node in IGW used three approaches to discover the IGW and communicate with it. The first one is the proactive approach [4], where the IGW broadcasts a packet periodically to announce its presence to the node within a transmission range based on time to live (TTL). The node outside the transmission range used a reactive approach [5]. The reactive approach node that 
wants to communicate sends a solicitation message to the IGW. A hybrid approach [6] combines both the proactive and reactive to cover nodes within the IGW advertisement and those out of the range of IGW. A recent approach is to adapt the periodicity advertisement and time to life of Internet gateway packet base on the topology change. The choice of the selection of IGW in some research is based on some parameters [7], such as link break [8]. Other metrics [9, 10] involve the calculation of the best route to discover the Internet gateway.

To study, design, and propose a new algorithm or improve performance, scholars need to use simulation tools such as NS2, OPNET, MATLAB, and OMNET. The author needs to insert specific parameters as input, such as the number of nodes, the number of IGW, transmission range, traffic send rate, traffic type, mobility model, pause time, packet size, traffic rate, etc. These parameters must be described in their research to determine how the result has been collected. Describing the parameters will also help other researchers compare their work with the existing one by using the same parameters.

These parameters' choice is crucial to the researcher in deciding which parameters details to use for their works. Most research authors are not sure what parameter to use in their research to analyze their proposed algorithm. This review paper aims to show scenarios parameters scholars used in IGW discovery in MANET and help new researchers to have a global view of parameters used in IGW for a better decision. This review analyses 72 proceeding papers and articles in different digital libraries selected: google scholar, IEEE Xplore, Elsevier, Springer, and snowball from 2010-2020. The review result shows that missing input parameters are still observed in most papers, which made it difficult for other researchers to compare their work with the existing one.

In the literature, we can see that they have been some similar research. The majority of those research focuses on input parameters in general, like in (Kurkowski et al., 2005) survey proceeding paper from 2000 to 2005. Their result shows that Random waypoint (RWP) and NS2 were the most used; they also observed that some papers had missing parameters. Another research [11] conducted a review from 2006 to 2010. They found out that missing parameters are still observed in some papers. In [12] a survey was done on 280 papers in a peer-to-peer network and found out that custom simulators tools were more used than NS2.

The rest of this review is organized as follows: Section 2 gives detail of the review methodology, the result is provided in Section 3, Section 4 describe our recommendation, and finally, Section 5 conclude the review.

\section{Review methodology}

This work's literature review includes articles and proceeding papers selected from different digital journals: IEEEexplorer, Springer, Elsevier, Google scholar, and snowball from years 2010 to 2020 . The criteria for selecting the paper were based on these keywords:" Internet gateway discovery in Mobile ad hoc networks", " Internet connectivity in MANET", "Hybrid network in MANET." We have collected 72 papers, and 
from those papers, we have extracted input parameters, as you can see in Figure 1. The input parameters' selection to calculate the percentage includes parameters used by two (2) or more authors. Parameters used by less than one (1) author were not part of the calculation.

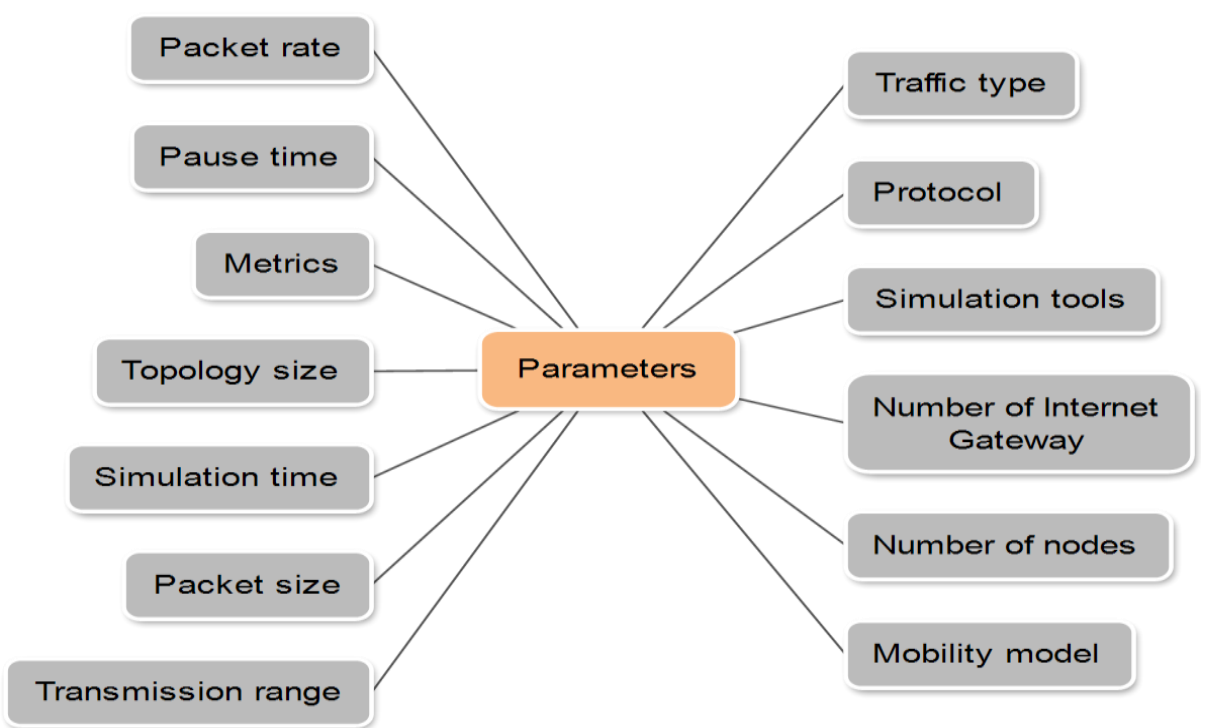

Fig. 1. Parameters extracted

This section describes some simulation parameters authors used in Internet Gateway discovery when designing their scenarios.

\section{Simulation Environment and Parameters}

This section describes the simulation parameters authors used in Internet Gateway discovery when designing their scenarios. It will analyze the parameters extracted in Figure 1.

Table 1 shows the simulation input parameters used in our review for all the 72 selected papers, and we have observed that missing parameters are still observed.

Table 1. Simulation input parameters usage over 72 papers

\begin{tabular}{|l|c|c|}
\hline \multicolumn{1}{|c|}{ Papers } & Percentage & Description \\
\hline 50 of 72 & 69.44 & stated the protocol used \\
\hline 51 of 72 & 70.83 & shows the number of nodes \\
\hline 38 of 72 & 52.78 & shows the number of IGW \\
\hline 40 of 72 & 55.56 & stated the transmission range \\
\hline 48 of 72 & 66.67 & stated the simulation duration \\
\hline 43 of 72 & 59.72 & stated the traffic type \\
\hline
\end{tabular}




\begin{tabular}{|l|c|c|}
\hline \multicolumn{1}{|c|}{ Papers } & Percentage & Description \\
\hline 49 of 72 & 68.06 & stated the mobility model \\
\hline 34 of 72 & 47.22 & stated the speed of the nodes \\
\hline 22 of 72 & 30.56 & stated the pause time \\
\hline 60 of 72 & 83.33 & shows the metrics \\
\hline 32 of 72 & 44.44 & stated the Packet size \\
\hline 41 of 72 & 56.94 & stated the topology size \\
\hline
\end{tabular}

\subsection{Protocol}

A MANET node who wants to communicate with a node on the Internet needs to use a protocol. AODV protocol was enhanced to support Internet messages and was called AODV+. It supports the discovery of an Internet gateway and the selection of it by the node in MANET. Table 2 shows a list of authors who used a particular protocol, and Figure 2 Shows $88 \%$ used AODV+, and 12\% used weighted load balancing AODV protocol (WLB-AODV).

Table 2. Protocol used in IGW

\begin{tabular}{|l|c|}
\hline \multicolumn{1}{|c|}{ Protocol } & Authors \\
\hline AODV+ & {$[5,6,8-10,14,17,21-42]$} \\
\hline WLB-AODV & {$[7,43-45]$} \\
\hline
\end{tabular}

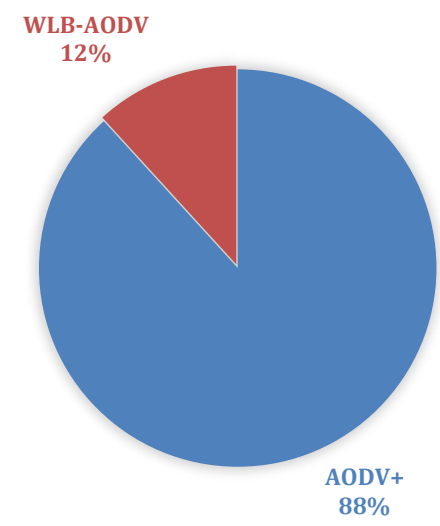

Fig. 2. Protocol usage in IGW

Other authors used different protocols, which is not shown in the table due to our review methodology selection. [13] used a RTMGwS to optimize the signal transmission to a specific area with no UTMS coverage. [14] created M-AODV+VRGSA, MAODV+-VRSA to help vehicular ad hoc network (VANET) node to choose a better IGW base on the speed and signal strength. [15] improved DYMO to secure the transmission of a packet in the discovery of an Internet Gateway. [16] created QOSDSDV to reduce the packet drop by creating a temporary link when the route is broken. [17] 
created AQA-AODV, [18] AGSA, [19] created a broadcast control-based routing protocol in VANET (BCRPV) for efficient bandwidth and link lifetime prediction. [20] created R-AODV+ for the selection of the IGW by calculating some metrics. Research in IGW compares their created protocols with the existing one AODV+ for performance has seen in Table 3.

Table 3. Protocol comparison

\begin{tabular}{|l|c|c|}
\hline \multicolumn{1}{|c|}{ Protocol } & Compared to & Authors \\
\hline WLB-AODV & AODV+ & {$[7,43-45]$} \\
\hline MAODV & AODV+ & {$[25]$} \\
\hline RTMGwS & $\begin{array}{c}\text { CMGM-AODV-Trust } \\
\text { SGS-AODV-Trust, SGS-AODV }\end{array}$ & {$[13]$} \\
\hline AQA-AODV & AODV+ & {$[17]$} \\
\hline PLB,PLB-MSC & AODV+ & {$[6]$} \\
\hline AGSA & AODV+ & {$[18]$} \\
\hline MMAMBA & AODMV & {$[46]$} \\
\hline BCRPV & PRB,AODV+ & {$[19]$} \\
\hline R-AODV+ & AODV+ & {$[20]$} \\
\hline
\end{tabular}

\subsection{Simulation tools}

In ad hoc network simulation tools play an essential role because it does not involve money to buy material and select geographical places to simulated the scenarios. Simulation can be an excellent option to test a protocol or algorithm before implementing it in a real environment to reduce the cost. In IGW, 75\% used NS2, 11\% used OPNET, $7 \%$ used OMNET++, and 4\% used MATLAB, as you can see in Figure 3. Some other simulation tools used by fewer authors are Veins [47] and Qualnet [15]. For a list of authors' usage, see Table 4. A previous survey in the ad hoc network [48] [12] found that $43.8 \%$ of the authors used NS2, [12] in their review found out that $10 \%$ of authors used NS2, and in IGW discovery majority of authors are still using NS2.

Table 4. Simulation comparison usage by author

\begin{tabular}{|l|c|}
\hline \multicolumn{1}{|c|}{ Simulation } & Author \\
\hline NS2 & {$[7,9,10,13,14,16,18,19,21,22,25-30,32,34,35,37,38,40,41,43,44,49-63]$} \\
\hline MATLAB & {$[6,64]$} \\
\hline OMNET++ & {$[4,65-67]$} \\
\hline OPNET & {$[5,23,36,68-70]$} \\
\hline
\end{tabular}




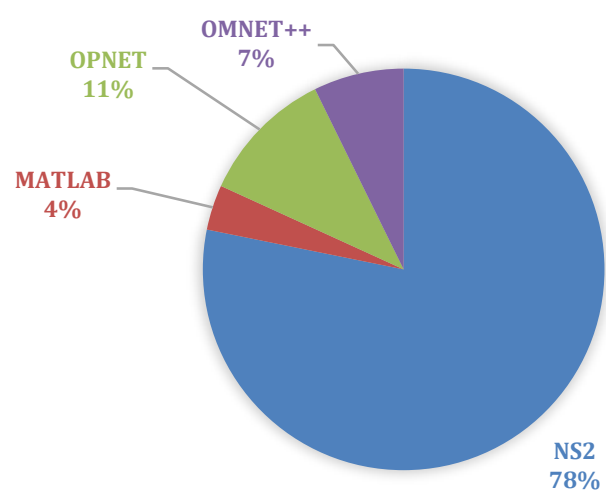

Fig. 3. Simulation comparison percentage

\subsection{Topology Size}

In Figure 4 we can see that a high percentage of utilization is on the $1000 \times 1000 \mathrm{~m}^{2}$ with $28 \%, 800 \times 500 \mathrm{~m}^{2}$ with $23 \%, 1200 \times 1200 \mathrm{~m}^{2}$ with $11 \%, 1200 \times 800 \mathrm{~m}^{2}$ with $9 \%$, $1200 \times 1200 \mathrm{~m}^{2}$ and $1200 \times 1200 \mathrm{~m}^{2}$ with $7 \%, 800 \times 700 \mathrm{~m}^{2}, 1200 \times 500 \mathrm{~m}^{2}$, and $1500 \times 800 \mathrm{~m}^{2}$ with $5 \%$ as seen in Table 5 . The smallest topology size was $11 \times 11 \mathrm{~m}^{2}$ [6] used in MATLAB, and the bigger topology size was $3000 \times 250 \mathrm{~m}^{2}$ [62] used in VANET. We have observed that few authors $[7,10,38,39,43,51]$ used two or three different topologies for the implementation of their proposed IGW protocol or algorithm for a better analysis when the size of the topology increase.

Table 5. Topology size usage by author

\begin{tabular}{|l|c|}
\hline \multicolumn{1}{|c|}{ Topology size $\mathbf{~ m}^{2}$} & Author \\
\hline $500 \times 500$ & {$[25,69,71]$} \\
\hline $800 \times 500$ & {$[7,9,10,29,40,43,45,51,63,72]$} \\
\hline $800 \times 700$ & {$[21,49]$} \\
\hline $1000 \times 1000$ & {$[4,5,10,18,27,32,36,39,41,49,51,68]$} \\
\hline $1200 \times 500$ & {$[44,73]$} \\
\hline $1200 \times 800$ & {$[37,55,57,66]$} \\
\hline $1200 \times 1200$ & {$[7,16,42,43,60]$} \\
\hline $1500 \times 300$ & {$[8,33,53]$} \\
\hline $1500 \times 800$ & {$[22,61]$} \\
\hline $2000 \times 2000$ & {$[39,54,74]$} \\
\hline
\end{tabular}


Paper-A Review on Parameters of Internet Gateway Discovery in MANETS

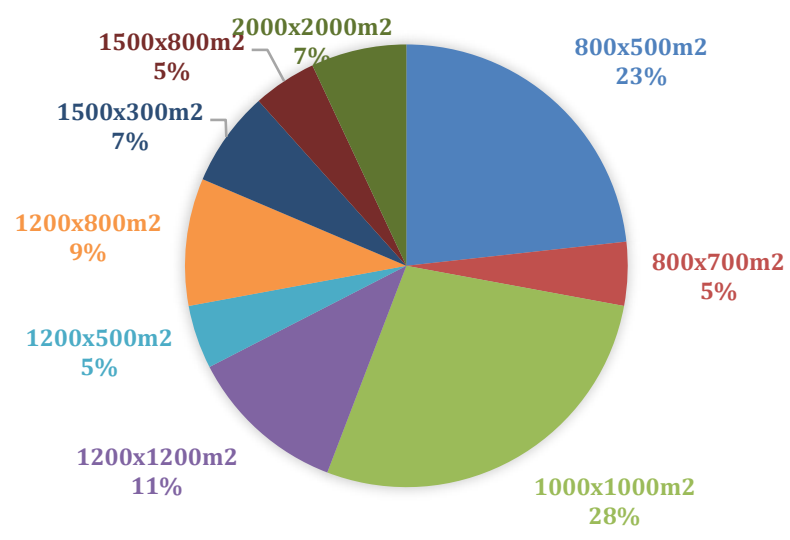

Fig. 4. Topology size percentage

\subsection{Pause time}

Figure 5 shows $45 \%$ used 10s, $23 \%$ used 5s, $14 \%$ used 60 s and $9 \%$ used 20 and 30 s. Table 6 shows the pause time usage by authors.

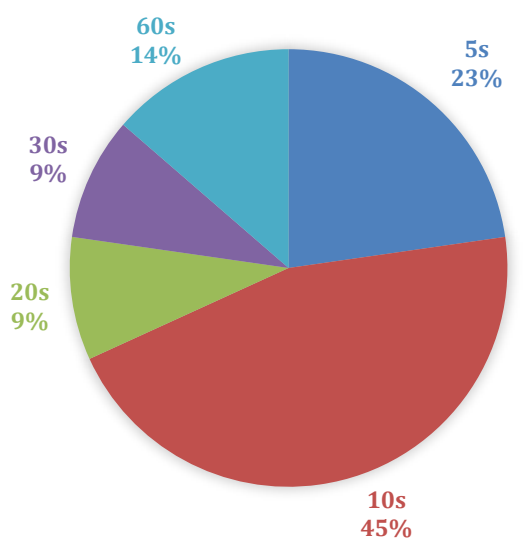

Fig. 5. Pause time percentage

Table 6. Pause Time usage by author

\begin{tabular}{|l|c|}
\hline \multicolumn{1}{|c|}{ Pause time in second } & Author \\
\hline 5 & {$[7,10,16,44,73]$} \\
\hline 10 & {$[8,17,22,29,33,39,42,52,56,61]$} \\
\hline 20 & {$[32,70]$} \\
\hline 30 & {$[5,33]$} \\
\hline 60 & {$[9,43,45]$} \\
\hline
\end{tabular}




\subsection{Transmission Range}

Figure 6 shows $82 \%$ used 250m, $8 \%$ used 150m, 100, and 300 was used 5\%. The highest transmission range was 500 used by [67] in OMNET++ simulation tools, and the work was done in VANET, where the focus was on the increase of the transmission range to cover a maximum of cars in VANET.

We have observed that a high percentage of authors used $250 \mathrm{~m}$, as seen in Table 7. We encourage authors to used different transmission range to provide the performance of the protocol base on the transmission range so that an improvement could be made.

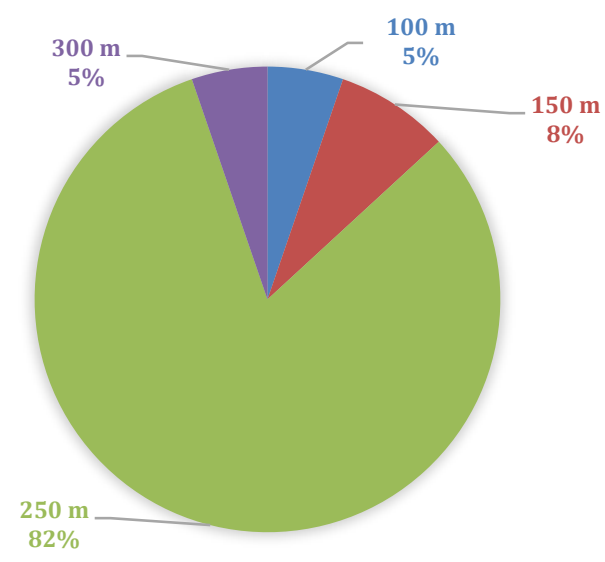

Fig. 6. Transmission range percentage usage by author

Table 7. Transmission range usage by author

\begin{tabular}{|c|c|}
\hline Transmission Range & Author \\
\hline 100 & {$[59,71]$} \\
\hline 150 & {$[39,41,75]$} \\
\hline 250 & {$[8-10,16,18,19,21,22,28,29,32,33,36,40,43-45,49,51,53,54$,} \\
& $56,57,60-62,66,68,69,72,73]$ \\
\hline 300 & {$[14,70]$} \\
\hline
\end{tabular}

\subsection{Simulation time}

The scenarios implemented need a specific time to show the performance analysis of a protocol. In Figure 7 shows that 29\% used 900s, 22\% used 1000s, 19\% used 600s, $15 \%$ used $500 \mathrm{~s}, 10 \%$ used $300 \mathrm{~s}$, and $5 \%$ used $120 \mathrm{~s}$. The high time simulation was 3600 used in a cluster discovery approach [68]. Table 8 lists authors who used a simulation time which was part of the calculation percentage.

In MANET, no predefined simulation time as standard has been proposed. The author choose any simulation time they want, which makes doubtful the result proposed. 


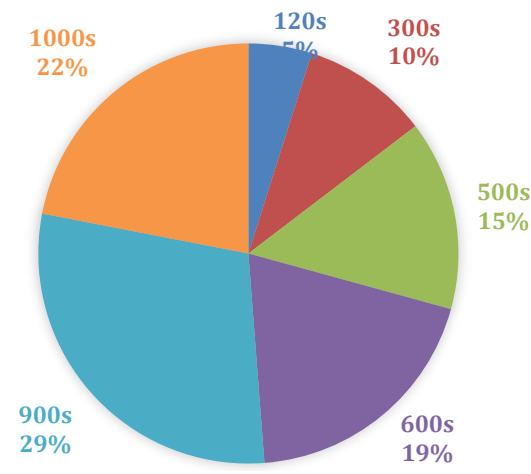

Fig. 7. Simulation time percentage usage

Table 8. Simulation time usage by author

\begin{tabular}{|l|c|}
\hline Simulation Time & Author \\
\hline 120 & {$[29,46]$} \\
\hline 300 & {$[17-19,62]$} \\
\hline 500 & {$[14,32,54,56,73]$} \\
\hline 600 & {$[4,5,30,41,49,60,65,70]$} \\
\hline 900 & {$[9,10,36,40,43,45,49,51,57,66,72]$} \\
\hline 1000 & {$[8,22,26,28,33,38,42,53,61]$} \\
\hline
\end{tabular}

\subsection{Metrics}

The metrics are used for the analysis of a protocol or algorithm created. Figure 8 shows that 38\% used End to End Delay (E2ED), 21\% used Packet Delivery Ratio (PDR), 15\% used Overhead, 10\% Throughput and Network Routing Load (NRL), and 6\% used Packet Delivery Fraction (PDF). Table 9 list the authors associated with the metrics used.

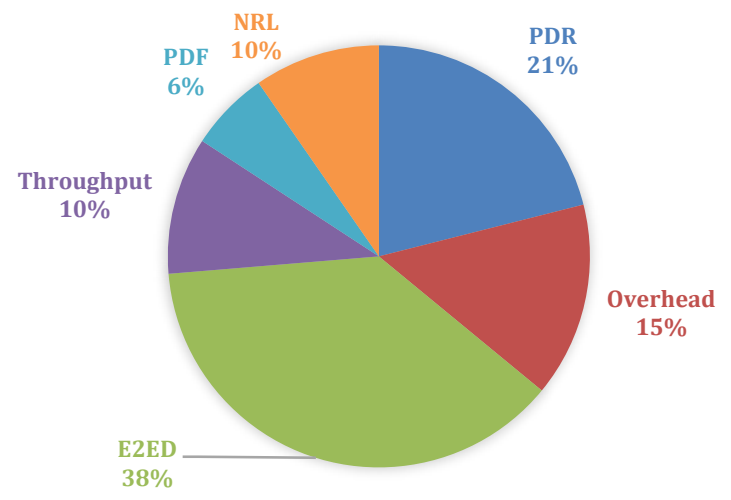

Fig. 8. Metrics percentage usage by author 
We have observed a combination of different metrics for the analysis of the performance of the network. Some specific metrics were also used like slot time [73], number of gateway broadcast operation [61], Balanced load Index[33], connectivity duration [67], handovers [47], bandwidth usage [59], Number of selected IGW[30]

Table 9. Metrics usage by author

\begin{tabular}{|l|c|}
\hline \multicolumn{1}{|c|}{ Metrics used } & Author \\
\hline PDR & {$[4,7,14,16,18,19,27,29,32,34,37,38,41,43-45,49,51,54-56,61,66,72]$} \\
\hline NRO, OVH & {$[8,13,14,16,26,32,33,39,40,42,49,53-56,62,72]$} \\
\hline E2ED & {$[4,7-9,13-17,19,21,25,27-30,32-34,36,38,40-46,49,51,54-57,61-63,65,68-$} \\
& $70,72,73]$ \\
\hline Throughput & {$[4,5,13,21,27,30,36,38,66,68,69,73]$} \\
\hline PDF & {$[13,25,30,40,57,62,63]$} \\
\hline NRL & {$[6,7,9,19,25,28,29,44,51,57,63]$} \\
\hline
\end{tabular}

\subsection{Number of Nodes}

In ad hoc networks, nodes are essential for communication; choosing the number of nodes will also impact the network's performance. Figure 9 shows $22 \%$ used 15 nodes, $21 \%$ used 50 nodes, $14 \%$ used 25 and 30 nodes, $11 \%$ used 100 nodes, $6 \%$ used 60 nodes, $3 \%$ used 12,40,45 and 200 nodes as calculate base on Table 11. The lowest number of nodes was 3 [56] used a topology size of $1000 \times 800 \mathrm{~m}^{2}$, and the highest one was $200[67,75]$ used in VANET. Table 10 shows authors who used a fixed number of the node with fixed topology. The number of nodes for certain authors varied with a different topology size. Some authors author did not vary the node with the topology size, and other authors used a fixed number of nodes with fixed topology size, as shown in Table 10. We can observe that most authors used fixed number of nodes with a fixed topology size. This approach is good but will not show the performance when the number of nodes increases or if the network's topology size increases.

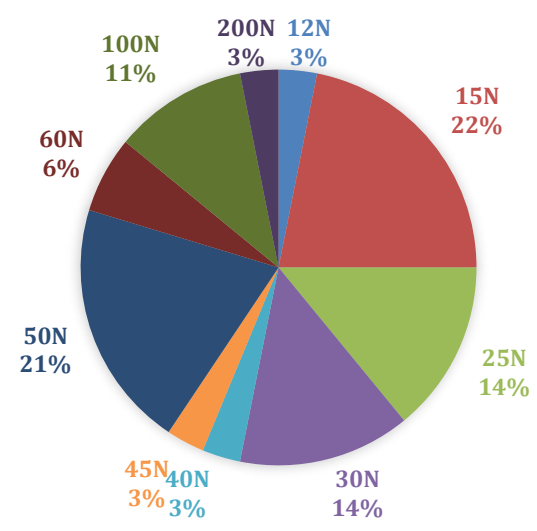

Fig. 9. Number of node percentage 
Table 10. Number of node base on topology change

\begin{tabular}{|l|l|}
\hline & \multicolumn{1}{|c|}{ Author } \\
\hline Fixed number of nodes with fixed topology size & $\begin{array}{l}{[5,6,8,9,15-18,21,22,28,29,32-34,36,37,40-} \\
42,49,55-57,60,63,66,68-70,72,73,76]\end{array}$ \\
\hline Varies number of node with fixed topology size & {$[23,25,53,54,61,63,71]$} \\
\hline Varies number of node and varies the topology size & {$[7,10,38,39,43,51]$} \\
\hline
\end{tabular}

Table 11. Number of node usage by author

\begin{tabular}{|l|c|}
\hline Number of Node & Author \\
\hline 12 & {$[38,77]$} \\
\hline 15 & {$[7,9,10,21,23,29,40,43,49,51,63,72,73,76]$} \\
\hline 25 & {$[5,7,10,25,34,36,38,44,51]$} \\
\hline 30 & {$[6,16,17,23,32,39,59,70,71]$} \\
\hline 40 & {$[53,71]$} \\
\hline 45 & {$[23,53]$} \\
\hline 50 & {$[8,22,25,33,37,39,41,43,47,53,55,57,71]$} \\
\hline 60 & {$[23,28,54,63]$} \\
\hline 100 & {$[15,25,39,42,54,60,66]$} \\
\hline 200 & {$[67,75]$} \\
\hline
\end{tabular}

\subsection{Number of IGW}

In Figure 10, 44\% used two (2) internet gateway, 18\% used three (3), 14\% used four (4), $11 \%$ used five (5) and $4 \%$ used one (1), Nine (9) and ten (10) IGW. Some author used a variation of the number of internet gateway in their simulation $[7,10,15,25,43$, $46,51,53,54,58,60,61,63]$. The lowest number of IGW was one (1), as you can see in the table 12, and the highest number of IGW nodes used was 100 [58] applied in VANET.

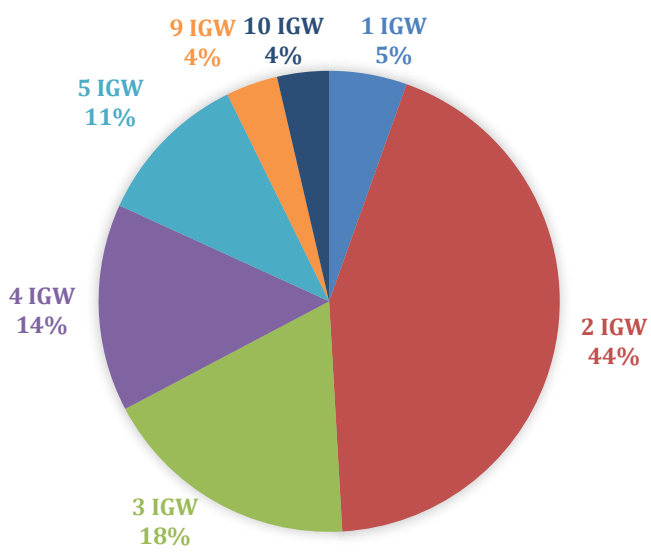

Fig. 10. Number of Internet Gateway percentage 
Table 12. Number of Internet gateway usage by author

\begin{tabular}{|l|c|}
\hline Number of IGW & Author \\
\hline 1 & {$[15,46,71]$} \\
\hline 2 & {$[7,9,10,17,21,28,29,37,38,40,42,43,49,51,53,54,56,57,60-63,73,76]$} \\
\hline 3 & {$[5,10,25,44,46,51,53,61,63,66]$} \\
\hline 4 & {$[15,32,39,49,53,54,60,70]$} \\
\hline 5 & {$[7,25,41,43,46,53]$} \\
\hline 9 & {$[15,59]$} \\
\hline 10 & {$[25,58]$} \\
\hline
\end{tabular}

\subsection{Packet Size}

The size of a packet is essential when sending a message in an ad hoc network. Table 13 shows the packet size and those authors who utilize it. Figure 11 show that $86 \%$ of authors used $512 \mathrm{~b}$ and $7 \%$ used $1024 \mathrm{~b}$ and $128 \mathrm{~b}$. The majority of authors used the predefined parameter settings from some simulation tools such as Network simulation 2 (NS2), which is 512b as a default parameter. Other authors also used the same packet size in OPNET [5, 69] and OMNET++ [66]. The smallest packet size was 120b[42], where they focus on stable links to discover the IGW in MANET with a topology size of $1200 \times 1200 \mathrm{~m}^{2}$. The largest packet size was 1024, as shown in Table 13, which they implemented in OPNET with a topology size vary from $600 x 600 \mathrm{~m}^{2}$ and $800 x 800 \mathrm{~m}^{2}$. We have observed that not authors have been using a different type of packet size for comparative analysis of their created protocol.

Table 13. Packet size usage by author

\begin{tabular}{|l|c|}
\hline \multicolumn{1}{|c|}{ Packet Size } & Author \\
\hline 128 & {$[33,71]$} \\
\hline 512 & {$[5,14,17-19,21,22,28,29,32,38,41,44,46,49,54-57,60,62,66,69,72,73]$} \\
\hline 1024 & {$[23,70]$} \\
\hline
\end{tabular}

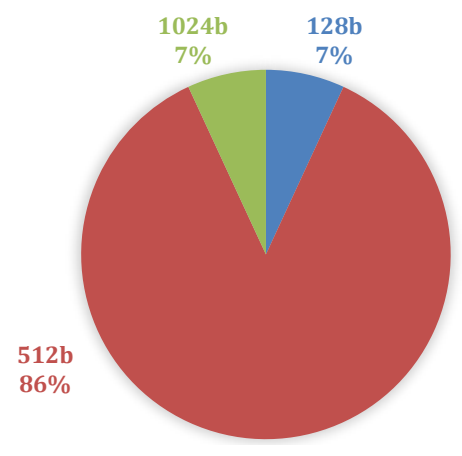

Fig. 11. Packet size Percentage 


\subsection{Traffic Type}

Figure 12 shows that $93 \%$ of the authors used the constant bit rate (CBR), and 7\% used the Variable Bit Rate (VBR) as shown in Table 14.

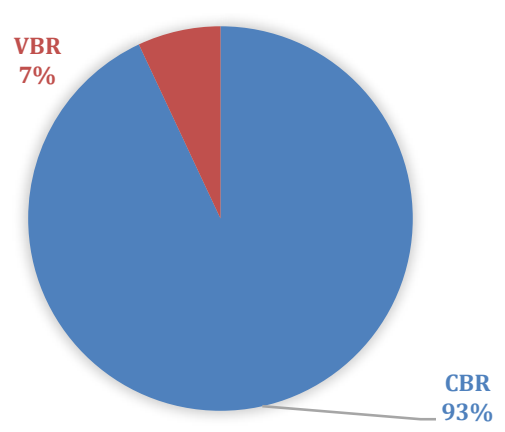

Fig. 12. Traffic type percentage

Table 14. Traffic type usage by author

\begin{tabular}{|l|c|}
\hline \multicolumn{1}{|c|}{ Traffic Type } & Author \\
\hline CBR & {$[4-6,9,10,14,16-19,22,27-29,32,33,36,38,40,41,43,44,46,49,51,53-57$,} \\
& $60-62,66,68-70,72,73,76]$ \\
\hline VBR & {$[8,26,42]$} \\
\hline
\end{tabular}

\subsection{Mobility Model}

Figure 13 shows that $73 \%$ used Random Way Point Mobility (RWP), $14 \%$ used SUMO, 9\% used Manhattan and 4\% used Reference Point Group Mobility (RPGM), and $4 \%$ used SUMO. Other mobility were Freeway mobility model [19], Radom direction mobile mobility (RDMM) [64], Time variant community mobility model (TVCM) [53], Radom Trip model [26]. For a list of authors who used a specific mobility model, see Table 15 . We have observed that only one author used two different mobility models for the performance of their work [42].

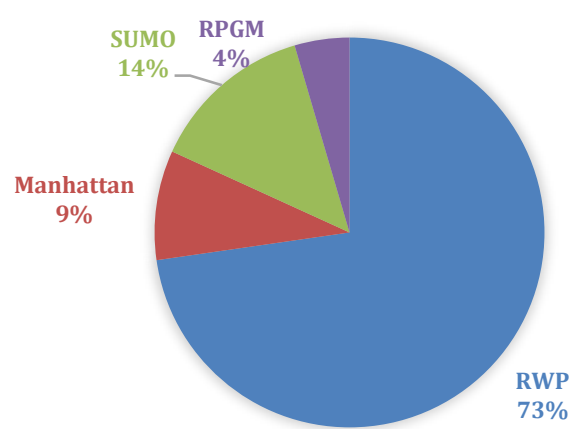

Fig. 13. Mobility model percentage 
Table 15. Mobility Model usage by author

\begin{tabular}{|l|c|}
\hline \multicolumn{1}{|c|}{ Mobility Model } & Author \\
\hline RWP & {$[5,7-10,15-17,21-23,28,29,32,33,38,39,41-44,49,51,60,61,63,66$,} \\
& $69-71,73,76]$ \\
\hline Manhattan & {$[50,54,58,59]$} \\
\hline SUMO & {$[13,14,30,47,62,67]$} \\
\hline RPGM & {$[36,68]$} \\
\hline
\end{tabular}

\subsection{Packet rate}

Figure 14 shows that $56 \%$ used 5 packets per second (p/s), $31 \%$ used $10 \mathrm{p} / \mathrm{s}$, and $13 \%$ used $20 \mathrm{p} / \mathrm{s}$, see Table 16 for a list of authors.

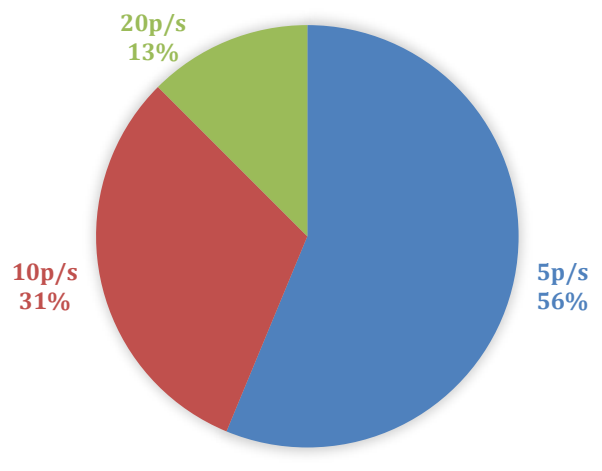

Fig. 14. Packet rate percentage

Table 16. Packet rate usage by author

\begin{tabular}{|l|c|}
\hline \multicolumn{1}{|c|}{ Packet rate in p/s } & Author \\
\hline 5 & {$[9,16,43,55-57,62,72,76]$} \\
\hline 10 & {$[15,26,32,49,53]$} \\
\hline 20 & {$[26,61]$} \\
\hline
\end{tabular}

\section{$4 \quad$ Recommendation}

We have observed that some parameters and protocols had a high percentage of authors' usage, making it a better choice to use by other authors in their simulation. However, the choice of parameters and protocol used in simulation tools depends on the research objective.

Wehave observed in Table 17 that the topology size does not vary accordingly to the number of nodes. A high number of nodes can have a small topology size; for example, number 10 shows 40 nodes used with a topology size of $500 \times 500 \mathrm{~m}^{2}$, and the same goes for number 15 with 50 nodes, but the topology size still $500 \times 500 \mathrm{~m}^{2}$. The same goes for Internet gateway numbers and simulation times. Arbitrary choice of parameters is more used in IGW, and this shows how the need for standardization of simulation 
parameters has to be put in place. Our proposition of recommended input parameters in Table 18 is based on the high utilization percentage in all the parameters described here. We also include the percentage with is closer to each other despite the high utilization.

Table 17. Summary of some parameters used in IGW

\begin{tabular}{|c|c|c|c|c|c|c|}
\hline No. & Nodes & $\begin{array}{l}\text { Topology } \\
\text { (M X M) }\end{array}$ & IGW & $\begin{array}{c}\text { Range } \\
\text { (M) }\end{array}$ & Simulation Time (S) & Packet Size (B) \\
\hline 1 & 3 & $1000 \times 800$ & 2 & 250 & 500 & 512 \\
\hline 2 & 10 & $1000 \times 1000$ & 4 & 250 & 500 & 512 \\
\hline 3 & 15 & $800 \times 700 \mathrm{~m}$ & 2 & 250 & 900 & 512 \\
\hline 4 & 15 & $1200 \times 500$ & 2 & 250 & 500 & 512 \\
\hline 5 & 15 & $800 \times 500$ & 2 & 250 & 120 & 512 \\
\hline 6 & 25 & $1200 \times 500$ & 3 & 250 & 900 & 512 \\
\hline 7 & 30 & $800 \times 800$ & 4 & 300 & 600 & 1024 \\
\hline 8 & 30 & $1000 \times 1000$ & 4 & 250 & 500 & 512 \\
\hline 9 & 30 & $500 \times 500$ & 1 & 100 & 180 & 128 \\
\hline 10 & 40 & $500 \times 500$ & 1 & 100 & 180 & 128 \\
\hline 11 & 40 & $1500 \times 300$ & 2 & 250 & 1000 & 320 \\
\hline 12 & 45 & $1500 \times 300$ & 3 & 250 & 1000 & 320 \\
\hline 13 & 50 & $1200 \times 800$ & 2 & 250 & 900 & 512 \\
\hline 14 & 50 & $1000 \times 1000$ & 5 & 150 & 600 & 512 \\
\hline 15 & 50 & $500 \times 500$ & 1 & 100 & 180 & 128 \\
\hline 16 & 50 & $1500 \times 300$ & 4 & 250 & 1000 & 320 \\
\hline 17 & 55 & $1500 \times 300$ & 5 & 250 & 1000 & 320 \\
\hline 18 & 60 & $1300 \times 800$ & 2 & 250 & 1000 & 512 \\
\hline 19 & 60 & $2000 \times 2000$ & 2 & 250 & 500 & 512 \\
\hline 20 & 100 & $1200 \times 1200$ & 2 & 250 & 600 & 512 \\
\hline 21 & 100 & $1200 \times 1200$ & 4 & 250 & 600 & 512 \\
\hline 22 & 100 & $1200 \times 1200$ & 8 & 250 & 600 & 512 \\
\hline 23 & 100 & $1200 \times 800$ & 3 & 250 & 900 & 512 \\
\hline 24 & 100 & $2000 \times 2000$ & 4 & 250 & 500 & 512 \\
\hline
\end{tabular}

Our recommendation to scholars in the Mobile ad hoc network and specifically in IGW is to ensure that all the parameters are well described and shown in the paper to facilitate comparative analysis. We encourage authors in Internet gateway to vary the number of the node with different topology sizes, vary the number of the internet gateway, use different mobility models, and vary the pause time to evaluate their proposed protocol better. We recommend the MANET community to develop a standardized simulation and environment input to make the result credible and acceptable by all researchers. 
Table 18. Proposed input parameters

\begin{tabular}{|l|c|}
\hline \multicolumn{1}{|c|}{ Parameter } & Value \\
\hline Simulation tools & NS2 \\
\hline Number of mobile nodes & $15,50,25,30$ \\
\hline Number of Gateway nodes & $2,3,4$ \\
\hline Topology size & 1000x100, 800x500 \\
\hline Traffic type & CBR \\
\hline Packet Size & 512 \\
\hline Transmission range & $250 \mathrm{~m}$ \\
\hline Pause time & $10 \mathrm{~s}$ \\
\hline Mobility model & RWP \\
\hline Simulation time & 900s, $1000 \mathrm{~s}, 600 \mathrm{~s}$ \\
\hline Ad hoc Routing protocol & AODV+ \\
\hline Packet rate & $5 \mathrm{p} / \mathrm{s}$ \\
\hline Metrics & E2ED, PDR, Overhead \\
\hline
\end{tabular}

\section{Conclusion}

The performance analysis of the IGW protocol depends on a variety of parameters that need to be taken into consideration before deciding what number of nodes, topology size, simulation time, and other parameters to choose. We found out that $88 \%$ of the author still used AODV+ as their base protocol for comparison or enhancement. NS2 had $78 \%$ of usage in terms of simulation tools, $250 \mathrm{~m}$ was the transmission range used with $82 \%$, 900 seconds was the simulation time with $25 \%$ of usage, $28 \%$ used $1000 \times 100 \mathrm{~m} 2$ as the topology size. E2ED got $38 \%$ as the hight metrics used in IGW, the number of Internet gateway used was two (2) with 44\%, 512byte was the Packet size with $86 \%$, traffic type was CBR with $93 \%$, RWP was the mobility model used with $70 \%, 10$ second was the pause time used with $45 \%$, and the packet rate was $5 \mathrm{p} / \mathrm{s}$. We have observed that some authors did not justify the choice of the parameters used in their paper. Other parameters were not given in some papers, as you can see in Table 1 , making it difficult for the researcher to compare their work with the existing one. In Section 4 we recommended the input parameters future research needs to use in their work. However, other parameters can be added base on the research objective of the authors. We hope that our review result will help the MANET community develop standardized Internet gateway researcher parameters as a reference.

\section{References}

[1] Arthur, M.P. and K. Kannan, Cross-layer based multiclass intrusion detection system for secure multicast communication of MANET in military networks. Wireless Networks, 2016. 22: p. 1035-1059. https://doi.org/10.1007/s11276-015-1065-2 
[2] Belgaum, M.R., et al., Secured Approach towards Reactive Routing Protocols Using Triple Factor in Mobile Ad Hoc Networks. Annals of Emerging Technologies in Computing, 2019. 3: p. 32-40. https://doi.org/10.33166/aetic.2019.02.004

[3] Kaur, P., D. Kaur, and R. Mahajan, Simulation Based Comparative Study of Routing Protocols Under Wormhole Attack in Manet. Wireless Personal Communications, 2017. 96: p. 47-63. https://doi.org/10.1007/s11277-017-4150-2

[4] Parvanak, A.R., M. Jahanshahi, and M. Dehghan, A cross-layer learning automata based gateway selection method in multi-radio multi-channel wireless mesh networks. Computing, 2019. 101: p. 1067-1090. https://doi.org/10.1007/s00607-018-0648-Z

[5] Kushwah, R., S. Tapaswi, and A. Kumar. Enhanced Gateway Deployment Scheme for Load Balancing in Heterogeneous Networks. in 2018 9th International Conference on Computing, Communication and Networking Technologies, ICCCNT 2018. 2018. IEEE. https://doi.org/10.1109/iccent.2018.8493848

[6] Prakash, J., R. Kumar, and J.P. Saini, Path load balancing adaptive gateway discovery in MANET-internet integration using PSO. International Journal of Intelligent Engineering \& System, 2017. 10(4): p. 235-244. https://doi.org/10.22266/ijies2017.0831.25

[7] Zaman, R.U., K.U.R. Khan, and A.V. Reddy. Load balanced fuzzy control based adaptive gateway discovery in Integrated Internet MANET. in International Conference on Computing and Communication Technologies. 2014. IEEE. https://doi.org/10.1109/iccct2 .2014 .7066713

[8] Yuste, A.J., et al., Adaptive gateway discovery for mobile ad hoc networks based on the characterisation of the link lifetime. IET Communications, 2011. 5: p. 2241-2249. https://doi.org/10.1049/iet-com.2010.0692

[9] Zaman, R.U., et al. Amelioration of load balanced gateway selection protocol in integrated Internet-MANET. in Proceedings of the 2016 2nd International Conference on Contemporary Computing and Informatics, IC3I 2016. 2016. IEEE. https://doi.org/10.1109/ ic3i.2016.7918793

[10] Zaman, R.U., et al. Enhancement of load balanced gateway selection in integrated InternetMANET using genetic algorithm. in 2016 4th International Conference on Parallel, Distributed and Grid Computing, PDGC 2016. 2016. https://doi.org/10.1109/pdgc.2016.7913221

[11] Hiranandani, D., K. Obraczka, and J.J. Garcia-Luna-Aceves, MANET protocol simulations considered harmful: The case for benchmarking. IEEE Wireless Communications, 2013. 20: p. 82-90. https://doi.org/10.1109/mwc.2013.6590054

[12] Naicken, S., et al., The state of peer-to-peer simulators and simulations. ACM SIGCOMM Computer Communication Review, 2007. 37(2): p. 95-98. https://doi.org/10.1145/12329 19.1232932

[13] Sharef, B., et al., Robust and trust dynamic mobile gateway selection in heterogeneous VANET-UMTS network. Vehicular communications, 2018. 12: p. 75-87. https://doi.org/ $\underline{10.1016 / \text { j.vehcom.2018.02.002 }}$

[14] Abada, D., et al. An Adaptive Vehicular Relay and Gateway Selection Scheme for Connecting VANETs to Internet via 4G LTE Cellular Network. in 2019 International Conference of Computer Science and Renewable Energies (ICCSRE). 2019. IEEE. https://doi.org/10.1109 /iccsre.2019.8807536

[15] Matsuda, T., et al., Gateway selection protocol in hybrid manet using dymo routing. Mobile Networks and Applications, 2010. 15(2): p. 205-215. https://doi.org/10.1007/s11036-009$\underline{0173-6}$

[16] Palani, K. and P. Ramamoorthy. Performance evaluation of QoS based DSDV protocol using an integration approach for hybrid networks. in 2014 International Conference on Green 
Computing Communication and Electrical Engineering (ICGCCEE). 2014. IEEE. https://doi.org/10.1109/icgccee.2014.6921390

[17] Castellanos-Hernández, W.E., J.C. Guerri-Cebollada, and M.E. Chacón-Osorio, A hybrid gateway discovery algorithm for supporting QoS communications in heterogeneous networks. Revista Facultad de Ingenieria, 2016. 2016: p. 80-88. https://doi.org/10.17533 ludea.redin.n78a11

[18] Ge, Z., T. Li, and X. Qiu. Anycast-based gateway selection algorithm for wireless mesh network. in ICCSE 2010 - 5th International Conference on Computer Science and Education, Final Program and Book of Abstracts. 2010. IEEE. https://doi.org/10.1109/iccse. 2010.5593638

[19] Ba, A.A., A. Hafid, and J. Drissi. Broadcast Control-Based Routing Protocol for Internet Access in VANETS. in 2011 7th International Wireless Communications and Mobile Computing Conference. 2011. IEEE. https://doi.org/10.1109/iwcmc.2011.5982802

[20] Syarif, A., et al. Adding gateway mode for R-AODV routing protocol in hybrid ad hoc network. in IEEE Region 10 Annual International Conference, Proceedings/TENCON. 2011. IEEE. https://doi.org/10.1109/tencon.2011.6129085

[21] Iqbal, S.M.A., et al. A novel strategy to discover internet gateways in mobile ad hoc networks. in Proceedings of 2010 13th International Conference on Computer and Information Technology, ICCIT 2010. 2010. IEEE. https://doi.org/10.1109/iccitechn.2010.5723914

[22] Xu, H., et al. On-demand gateway broadcast scheme for connecting mobile ad hoc networks to the Internet. in Proceedings of 2014 International Conference on Smart Computing, SMARTCOMP 2014. 2014. IEEE. https://doi.org/10.1109/smartcomp.2014.7043847

[23] Uddin, J. and J.-M. Kim, A Virtual Mobile Ad-Hoc Network Model to Improve Internet Connectivity among Heterogeneous Mobile Devices. Journal of the Korea Society of Computer and Information, 2014. 19: p. 31-41. https://doi.org/10.9708/jksci.2014.19.1.031

[24] Xu, H., et al., Gateway pheromone-based adaptive internet access scheme for mobile ad hoc networks. International Journal of Ad Hoc and Ubiquitous Computing, 2015. 19(1-2): p. 5061. https://doi.org/10.1504/ijahuc.2015.069493

[25] Hassan, H., P. Trwoga, and I. Kale. If-manet: Interoperable framework for mobile ad hoc networks. in International Conference on Computer Networks. 2015. Springer. https://doi.org/10.1007/978-3-319-19419-6_6

[26] Yuste-Delgado, A.J., et al., Improving hybrid ad hoc networks: The election of gateways. Applied Soft Computing, 2016. 41: p. 1-14. https://doi.org/10.1016/j.asoc.2015.12.012

[27] Das, B., et al. A new approach for gateway-level load balancing of wmns through k-means clustering. in Proceedings - 2014 6th International Conference on Computational Intelligence and Communication Networks, CICN 2014. 2014. https://doi.org/10.1109/ cicn.2014.118

[28] Majumder, S. and Asaduzzaman. A hybrid gateway discovery method for mobile ad hoc networks. in 2014 International Conference on Informatics, Electronics and Vision, ICIEV 2014. 2014. IEEE. https://doi.org/10.1109/iciev.2014.6850760

[29] Zaman, R.U., et al. Traffic priority based gateway selection in Integrated Internet-MANET. in Proceedings of the 2016 2nd International Conference on Applied and Theoretical Computing and Communication Technology, iCATccT 2016. 2017. IEEE. https://doi.org/ 10.1109/icatcct.2016.7911958

[30] Fouladian, M., F. Hendessi, and M.A. Pourmina, Using AHP and Interval VIKOR Methods to Gateway Selection in Integrated VANET and 3G Heterogeneous Wireless Networks in Sparse Situations. Arabian Journal for Science and Engineering, 2016. 41: p. 2787-2800. https://doi.org/10.1007/s13369-015-2010-5 
[31] Kushwah, R., S. Tapaswi, and A. Kumar. Enhanced gateway deployment scheme for load balancing in heterogeneous networks. in 2018 9th International Conference on Computing, Communication and Networking Technologies (ICCCNT). 2018. IEEE. https://doi.org/ $\underline{10.1109 / \text { iccent.2018.8493848 }}$

[32] Iqbal, S.M.A. and M.H. Kabir. Internet gateway discovery and selection scheme in mobile ad hoc network. in 14th International Conference on Computer and Information Technology, ICCIT 2011. 2011. https://doi.org/10.1109/iccitechn.2011.6164867

[33] Yuste, A.J., et al. Improved scheme for adaptive gateway discovery in hybrid MANET. in Proceedings - International Conference on Distributed Computing Systems. 2010. https://doi.org/10.1109/icdcsw.2010.63

[34] Singh, D. and D. Kim. Performance analysis of gateway discovery techniques: IPv6-based wireless sensor networks. in Proceedings - 2nd International Conference on Evolving Internet, Internet 2010, 1st International Conference on Access Networks, Services and Technologies, Access 2010. 2010. IEEE. https://doi.org/10.1109/internet.2010.47

[35] Bin, S., H. Yangcheng, and H. Zhonggong. Optimization gateway discovery mechanisms for hybrid ad hoc networks. in 2011 International Conference on Consumer Electronics, Communications and Networks, CECNet 2011 - Proceedings. 2011. IEEE. https://doi.org/ $\underline{10.1109 / \mathrm{cecnet} .2011 .5768567}$

[36] Bagwari, A. and R. Jee. Enhancing the MANET Nodes of Hierarchical Architecture for Communication between Mobile Ad Hoc Network and Internet Using Cluster Head Gateway. in 2011 International Conference on Computational Intelligence and Communication Networks. 2011. IEEE. https://doi.org/10.1109/cicn.2011.71

[37] Manoharan, R. and S. Mohanalakshmie. A trust based gateway selection scheme for integration of manet with internet. in 2011 International Conference on Recent Trends in Information Technology (ICRTIT). 2011. IEEE. https://doi.org/10.1109/icrtit.2011.5972415

[38] Saluja, R.K. and R. Shrivastava. A scenario based approach for gateway discovery using Manet routing protocol. in 2012 International Conference on Computer Communication and Informatics, ICCCI 2012. 2012. IEEE. https://doi.org/10.1109/iccci.2012.6158865

[39] Yan, Y., et al. Address Auto-configuration in MANET with multiple gateways: Analysis and measurement. in IEEE International Conference on Networks, ICON. 2012. IEEE. https://doi.org/10.1109/icon.2012.6506550

[40] Ahmed, M.A. and K.U.R. Khan. Trust based secure gateway discovery mechanism for integrated internet and MANET. in International conference on distributed computing and internet technology. 2013. Springer. https://doi.org/10.1007/978-3-642-36071-8_7

[41] Yan, Y., et al. QoS-based gateway selection in MANET with Internet connectivity. in 2013 15th International Conference on Advanced Communications Technology (ICACT). 2013. IEEE.

[42] Yuste, A.J., A. Trivino, and E. Casilari, Type-2 fuzzy decision support system to optimise MANET integration into infrastructure-based wireless systems. Expert Systems with Applications, 2013. 40(7): p. 2552-2567. https://doi.org/10.1016/j.eswa.2012.10.063

[43] Zaman, R.U., K.U.R. Khan, and A.V. Reddy. Mamdani Fuzzy Control based adaptive gateway discovery for ubiquitous Internet access in MANET. in 2014 Annual IEEE India Conference (INDICON). 2014. IEEE. https://doi.org/10.1109/indicon.2014.7030593

[44] Zaman, R.U., K.U.R. Khan, and A.V. Reddy, Gateway load balancing in integrated internetMANET using WLB-AODV. ICWET 2010 - International Conference and Workshop on Emerging Trends in Technology 2010, Conference Proceedings, 2010: p. 411-416. https://doi.org/10.1145/1741906.1741994 
[45] Zaman, R.U., K.U. Rahman Khan, and A. Venugopal Reddy. Weighted load balanced adaptive gateway discovery in integrated internet MANET. in International Conference on Distributed Computing and Internet Technology. 2015. https://doi.org/10.1007/978-3-319$\underline{14977-6 \_22}$

[46] Song, L., J. Cao, and X.J. Yang. Multi-path anycast routing based on ant colony optimization in multi-gateway WMN. in ICCSE 2010 - 5th International Conference on Computer Science and Education, Final Program and Book of Abstracts. 2010. IEEE. https://doi.org/10.1109/iccse.2010.5593635

[47] Hagenauer, F., et al., Vehicular micro cloud in action: On gateway selection and gateway handovers. Ad Hoc Networks, 2018. 78: p. 73-83. https://doi.org/10.1016/j.adhoc. 2018.05.014

[48] Kurkowski, S., T. Camp, and M. Colagrosso. MANET simulation studies: the incredibles. in ACM SIGMOBILE Mobile Computing and Communications Review. 2005. https://doi.org/10.1145/1096166.1096174

[49] Asif Iqbal, S.M. and M. Humayun Kabir. An improved internet gateway discovery and selection scheme in Mobile Ad Hoc Network. in ICECE 2010 - 6th International Conference on Electrical and Computer Engineering. 2010. IEEE. https://doi.org/10.1109/icelce. $\underline{2010.5700706}$

[50] Abrougui, K., A. Boukerche, and R.W.N. Pazzi, Location-aided gateway advertisement and discovery protocol for VANets. IEEE Transactions on Vehicular Technology, 2010. 59: p. 3843-3858. https://doi.org/10.1109/tvt.2010.2064796

[51] Zaman, R.U., K.U.R. Khan, and A.V. Reddy. Path Load Balanced-Fuzzy Logic based Adaptive Gateway Discovery in integrated Internet-MANET. in Proceedings of 2012 2nd IEEE International Conference on Parallel, Distributed and Grid Computing, PDGC 2012. 2012. IEEE. https://doi.org/10.1109/pdgc.2012.6449934

[52] Yuste, A.J., et al. An adaptive genetic fuzzy control gateway discovery to interconnect hybrid MANETs. in IEEE Wireless Communications and Networking Conference, WCNC. 2010. https://doi.org/10.1109/wcnc.2009.4917568

[53] Yuste, A.J., et al., Using Fuzzy Logic in Hybrid Multihop Wireless Networks. International Journal of Wireless \& Mobile Networks, 2010. 2: p. 96-108. https://doi.org/10.5121/ijwmn. 2010.2307

[54] Lin, Y.-W., J.-M. Shen, and H.-C. Weng. Gateway discovery in VANET cloud. in 2011 IEEE international conference on high performance computing and communications. 2011. IEEE. https://doi.org/10.1109/hpcc.2011.138

[55] Li, X. and Z. Zhu. A gateway discovery method for MANET accessing Internet based on overhead control. in 7th International Conference on Wireless Communications, Networking and Mobile Computing, WiCOM 2011. 2011. https://doi.org/10.1109/wicom. $\underline{2011.6040424}$

[56] Syarif, A. and R.F. Sari, Performance analysis of AODV-UI routing protocol with energy consumption improvement under mobility models in hybrid ad hoc network. International Journal on Computer Science and Engineering, 2011. 3(7): p. 2904-2918.

[57] Majumder, K., S. Ray, and S.K. Sarkar. Implementation and performance analysis of the gateway discovery approaches in the integrated MANET-Internet scenario. in 2011 IEEE 3rd International Conference on Communication Software and Networks, ICCSN 2011. 2011. IEEE. https://doi.org/10.1109/iccsn.2011.6014965

[58] Abrougui, K., A. Boukerche, and Y. Wang. Secure gateway localization and communication system for vehicular ad hoc networks. in GLOBECOM - IEEE Global Telecommunications Conference. 2012. IEEE. https://doi.org/10.1109/glocom.2012.6503144 
[59] Aljeri, N., et al. A Performance evaluation of load balancing and QoS-aware gateway discovery protocol for VANETs. in 2013 27th International Conference on Advanced Information Networking and Applications Workshops. 2013. IEEE. https://doi.org/ 10.1109/waina.2013.232

[60] Yan, Y., et al. Load balancing routing algorithm among multiple gateways in MANET with Internet connectivity. in 16th International Conference on Advanced Communication Technology. 2014. IEEE. https://doi.org/10.1109/icact.2014.6778987

[61] Xu, H., L. Ju, and Z. Jia, Enhance internet access ability for ad hoc network with on-demand gateway broadcast strategy. International Journal of Wireless Information Networks, 2015. 22(4): p. 415-427. https://doi.org/10.1007/s10776-015-0290-Z

[62] Wantoro, J. and I. Mustika. M-AODV+: An extension of AODV+ routing protocol for supporting vehicle-to-vehicle communication in vehicular ad hoc networks. in Proceedings IEEE COMNETSAT 2014: 2014 IEEE International Conference on Communication, Network and Satellite. 2014. IEEE. https://doi.org/10.1109/comnetsat.2014.7050523

[63] Srivastava, P. and R. Kumar, A timestamp-based adaptive gateway discovery algorithm for ubiquitous internet access in MANET, in Next-generation networks. 2018, Springer. p. 153162. https://doi.org/10.1007/978-981-10-6005-2_17

[64] Nitti, M. and L. Atzori. Modeling of network connectivity in multi-homed hybrid ad hoc networks. in International Conference on Mobile Multimedia Communications. 2011. Springer. https://doi.org/10.41 08/icst.mobimedia2009.7492

[65] Benrhaiem, W., A.S. Hafid, and P.K. Sahu. Multi-hop reliability for broadcast-based VANET in city environments. in 2016 IEEE International Conference on Communications, ICC 2016. 2016. IEEE. https://doi.org/10.1109/icc.2016.7511084

Mahiddin, N.A. and N.I. Sarkar. Improving the performance of MANET gateway selection scheme for disaster recovery. in 2016 IEEE 18th International Conference on High Performance Computing and Communications; IEEE 14th International Conference on Smart City; IEEE 2nd International Conference on Data Science and Systems (HPCC/SmartCity/DSS). 2016. IEEE. https://doi.org/10.1109/hpcc-smartcity-dss.2016. $\underline{0130}$

[67] Bhore, A.K., A. Sharma, and U. Bhattacharya. Multi-criteria mobile gateway selection approach in vehicular internet. in 2017 International Conference on Communication and Signal Processing (ICCSP). 2017. IEEE. https://doi.org/10.1109/iccsp.2017.8286764

[68] Gowri, R. and A. Bagwari. A hierarchical architecture for Mobile ad hoc Network with internet using cluster head gateway. in Proceedings - 2011 International Conference on Communication Systems and Network Technologies, CSNT 2011. 2011. IEEE. https://doi.org/10.1109/csnt.2011.27

[69] Baniya, B.K., et al. Internet gateway routing for MANET. in Proceedings - 2010 International Conference on Cyber-Enabled Distributed Computing and Knowledge Discovery, CyberC 2010. 2010. IEEE. https://doi.org/10.1109/cyberc.2010.44

[70] Kushwah, R., et al., Gateway load balancing using multiple QoS parameters in a hybrid MANET. Wireless Networks, 2018. 24(4): p. 1071-1082. https://doi.org/10.1007/s11276$\underline{016-1391-\mathrm{Z}}$

[71] Shimizu, M. and K. Takami. Improving communication quality by considering route stability for inter-gateway mobile ad-hoc networks. in International Conference on ICT Convergence. 2014. IEEE. https://doi.org/10.1109/ictc.2014.6983103

[72] Zaman, R.U. and C. Mjcet. An Effective Gateway Discovery Mechanism in an Integrated Internet-MANET ( IIM ). 2010.

[73] Pandey, A., et al. A fuzzy-timestamp based adaptive gateway discovery protocol in integrated Internet-MANET. in 2015 International Conference on Advances in Computing, 
Communications and Informatics, ICACCI 2015. 2015. IEEE. https://doi.org/10.110 9/icacci.2015.7275787

[74] Idrissi, A., et al. Gateway selection in vehicular ad-hoc network. in 2015 5th International Conference on Information \& Communication Technology and Accessibility (ICTA). 2015. IEEE. https://doi.org/10.1109/icta.2015.7426937

[75] Idrissi, A., et al. Gateway selection in vehicular ad-hoc network. in 2015 5th International Conference on Information \& Communication Technology and Accessibility (ICTA). 2015. IEEE. https://doi.org/10.1109/icta.2015.7426937

[76] Ju, K., et al., An efficient gateway discovery algorithm with delay guarantee for VANET3G heterogeneous networks. Wireless Personal Communications, 2014. 77: p. 2019-2036. https://doi.org/10.1007/s11277-014-1622-5

[77] Zaman, R.U., K.U.R. Khan, and A.V. Reddy. Weighted Load Balanced Adaptive Gateway Discovery in Integrated Internet MANET. in International Conference on Distributed Computing and Internet Technology. 2015. Springer. https://doi.org/10.1007/978-3-319-14977$\underline{622}$

[78] Omar, H.A., W. Zhuang, and L. Li. On multihop communications for in-vehicle Internet access based on a TDMA MAC protocol. in Proceedings - IEEE INFOCOM. 2014 https://doi.org/10.1109/infocom.2014.6848115

\section{Authors}

Husna Osman is with Universiti Kuala Lumpur, Malaysia Insitute of Information Technology, Kuala Lumpur, Malaysia.

Mufind Mukaz Ebedon is with Universiti Kuala Lumpur, Malaysia Insitute of Information Technology, Kuala Lumpur, Malaysia.

Amna Saad is with Universiti Kuala Lumpur, Malaysia Insitute of Information Technology, Kuala Lumpur, Malaysia.

Article submitted 2021-06-05. Resubmitted 2021-07-15. Final acceptance 2021-07-15. Final version published as submitted by the authors. 